\title{
The diagnostic utility of a genetics evaluation in children with pervasive developmental disorders
}

Omar A. Abdul-Rahman, MD, and Louanne Hudgins, MD

\begin{abstract}
Purpose: A genetics evaluation of children with pervasive developmental disorders (PDDs) identifies a diagnosis in $6 \%$ to $15 \%$ of cases. However, previous studies have not measured the incidence of genetic disorders among children with autistic-like features who do not necessarily meet the Diagnostic and Statistical Manual for Mental Disorders, Fourth Edition criteria for PDD. Methods: We identified 101 patients at our institution referred for PDD, autism, Asperger syndrome, or autistic features. Seventy-eight were males and 23 were females, giving a male-to-female ratio of 3.4:1. No diagnosis was identified on examination alone, although Rett syndrome was suspected in six females. Seventeen patients did not undergo any type of testing because of noncompliance. Results: Of the remaining 84 patients analyzed, seven (8.3\%) were found to have abnormalities on testing. Three chromosomal anomalies were found: one with $5 \mathrm{p}$ duplication, one with low-level mosaicism for trisomy 21 , and one with an unbalanced 10;22 translocation. Three females were diagnosed with Rett syndrome after MECP2 analysis identified a disease-causing mutation. The remaining patient was found to have an elevated urine orotic acid, with a normal ammonia level, of unknown significance. Conclusion: On the basis of our series, the yield of a genetics evaluation in patients with features of PDD who do not necessarily meet the Diagnostic and Statistical Manual for Mental Disorders, Fourth Edition criteria is 8.3\%. Approximately half of these were the result of a chromosomal abnormality. Three cases of Rett syndrome were identified for which autistic behaviors are a well-described feature. These findings suggest that a high-resolution karyotype provides the greatest diagnostic yield for patients with autistic-like features. MECP2 analysis should be considered for females who present with autistic behaviors. Genet
\end{abstract} Med 2006:8(1):50-54.

Key Words: pervasive developmental disorder, autism, autistic features, chromosomal abnormalities, Rett syndrome

The pervasive developmental disorders (PDDs) constitute a group of disorders characterized by impairments in the developmental domains of social interaction and communication in the presence of repetitive or stereotypical behaviors. PDD can be further categorized into autistic disorder, childhood disintegrative disorder, Asperger syndrome, Rett syndrome, or PDD not otherwise specified. The classification of these disorders depends on the degree of impairment and involvement of all or some of the domains mentioned previously. The Diagnostic and Statistical Manual for Mental Disorders, Fourth Edition (DSM-IV) criteria outlines the definitions of each disorder and lists diagnostic criteria required for the diagnosis of PDD. Planning for the DSM-V is already under way with the intention of using clinical neuroscience research to guide the development of a pathophysiologically based classification.

\footnotetext{
From the Division of Medical Genetics, Department of Pediatrics, Stanford University, Stanford, California.

Omar A. Abdul-Rahman, MD, 300 Pasteur Drive, H-315, Stanford, CA 94305.

Received: April 28, 2005.

Accepted: October 31, 2005.
}

DOI: 10.1097/01.gim.0000195304.45116.96
Autistic disorder (or autism) is the most studied entity, and evidence for genetic causes continues to be gathered. For example, it is well known that the recurrence risk for siblings of affected individuals is significantly higher than for the general population. ${ }^{1}$ In addition, twin studies have shown that concordance rates for monozygotic twins are far greater than similar rates for dizygotic twins. ${ }^{2}$ Finally, a number of susceptibility loci identified in familial cases of autism have been identified.

Approximately $90 \%$ to $95 \%$ of autism is idiopathic in nature with the remainder believed to be the result of a number of different causes including environmental agents such as rubella, chromosomal abnormalities, and single gene disorders such as tuberous sclerosis complex and fragile $\mathrm{X}$ syndrome. As the sophistication of genetic testing improves, an increasing number of causes are expected to be identified in idiopathic autism. The routine evaluation and management of children with autism and PDD involve a multidisciplinary approach. Consultations from neurologists, behavioral/developmental pediatricians, and physical and occupational therapists are frequently sought. Recently, because of the identification of heritable and genetic causes, clinical geneticists are increasingly called on to assist in the diagnostic evaluation of autistic children. A number of studies over the last decade identifying a 
multitude of genetic causes have been published with recommendations regarding cytogenetic and molecular testing, primarily for individuals with autism. The purpose of this study was to perform a retrospective analysis of patients referred to our institution in an effort to make specific recommendations regarding genetic testing in the population of patients referred for autistic-like features with or without a formal PDD/autism diagnosis.

\section{MATERIALS AND METHODS}

The genetics database at Stanford University was searched using the following key words: autism, autistic features, PDD, or Asperger syndrome. The keywords were entered in fields for both primary and secondary reasons for referral. Retrospective chart analysis was then performed to identify age, race, gender, results of clinical and laboratory evaluations, and final diagnosis. A thorough review of patients not referred primarily for the aforementioned keywords was performed to ascertain the primary reason for referral and to determine whether inclusion in our study was appropriate. Patients primarily referred for developmental delay or mental retardation were included in the study. Any patient with major congenital anomalies was excluded from the study. With this technique, we were able to identify 101 patients referred to our institution for a genetics evaluation from July 1998 to May 2004.

\section{RESULTS}

Of the 101 patients identified, 78 were males and 23 were females, resulting in a 3.4:1 male-to-female ratio. Previous studies have identified similar gender discrepancies in patients with autism and PDD. ${ }^{1,3,4}$ The patients ranged in age from 36 months to 38 years with a mean age of 8.8 years. Additional demographic information is provided in Table 1.

No diagnosis was made by clinical evaluation alone. However, Rett syndrome was suspected in six females. The type of laboratory testing was examiner-dependent and consisted of 83 karyotypes, 67 fragile $\mathrm{X}$ molecular analyses, 29 fluorescence in situ hybridization (FISH) analyses for 22q13 deletion, and 20 FISH analyses for 15q duplication. Six females underwent MECP2 sequencing. Some type of metabolic testing was performed in 53 patients and at a minimum required serum lactate level, blood ammonia level, plasma amino acid analysis, and urine organic acid analysis. Urine purine and pyrimidine levels were performed in 13 patients. Seventeen patients were noncompliant with the recommended testing, either because of lack of insurance approval or prohibitive travel requirements. Table 2 summarizes the laboratory evaluations performed.

Of the 84 patients tested, 7 (8.3\%) were found to have abnormalities on testing. Two patients were found to have chromosomal abnormalities on routine cytogenetic testing. A partial inverted duplication of the terminal portion of the short arm of chromosome 5 was identified in a male child. A female was identified with mosaic trisomy 21 in 8 of 50 lymphocytes and in 3 of 20 skin fibroblasts. It was not clear whether this
Table 1

Demographic information and reason for referral of the patient population

\begin{tabular}{lc}
\hline $\mathrm{N}$ & 101 \\
Males & 78 \\
Females & 23 \\
Age & $2.7-38$ years \\
$\quad$ Mean & 8.6 years \\
Median & 7.5 years \\
Primary reason for referral & \\
PDD/autism & 63 \\
Asperger syndrome & 7 \\
Autistic features & 7 \\
Developmental delay/mental retardation & 20 \\
a Other & 4 \\
Ethnicity & \\
Caucasian & 53 \\
Asian & 18 \\
Hispanic & 17 \\
Mixed/Other & 13 \\
\hline
\end{tabular}

$\overline{{ }^{a}}$ This category includes patients referred primarily for other conditions such as obesity, albinism, and maternal alcohol use.

low-level mosaicism was the cause of her autism; however, extensive testing for other possibilities was unrevealing. None of the patients with chromosome abnormalities were noted to be dysmorphic by a clinical geneticist.

High-resolution cytogenetic testing, defined as a band resolution of greater than 550, identified a female with an unbalanced 10;22 translocation resulting in monosomy $22 \mathrm{q}$ and trisomy 10q. FISH analysis showed only one hybridization signal with the arylsulfatase A probe, which is absent in the distal $22 \mathrm{q} 13$ deletion syndrome. The mother of the proband was found to be a carrier of a balanced 10;22 translocation. Routing karyotype analysis on this patient was normal.

Three of the six females tested for MECP2 mutations had positive results. One patient presented to the genetics clinic at 25 months with developmental delay and autistic features. No diagnosis was made at that time; however, she was referred back to genetics after she developed loss of hand skills. MECP2 sequencing demonstrated a premature stop codon, R270X. The other two females presented with more classic features of Rett syndrome, both at 4 years of age. These features included developmental regression, stereotypical hand movements, autistic-like features, and acquired microcephaly. MECP2 sequencing in both patients identified a premature stop codon in one patient (R168X) and a frameshift mutation in the other (852delAAAG).

One patient was identified with elevated urine orotic acid on organic acid analysis. Quantitative testing demonstrated a level of $12.2 \mathrm{mmol} / \mathrm{mol}$ of creatinine (normal $0.5-3.3 \mathrm{mmol} / \mathrm{mol} /$ creatinine). Further metabolic testing demonstrated normal 
Table 2

Laboratory evaluations performed in the patient population

\begin{tabular}{lcc}
\hline $\begin{array}{l}\text { Laboratory test } \\
\begin{array}{l}\text { Routine karyotype (band } \\
\text { resolution > 400) }\end{array}\end{array}$ & $\begin{array}{c}\text { No. of patients } \\
(\%)\end{array}$ & $\begin{array}{c}\text { Positive tests } \\
(\%)\end{array}$ \\
$\begin{array}{l}\text { High-resolution karyotype (band } \\
\text { resolution >550) }\end{array}$ & $44(52.4)$ & $3(6.8)$ \\
Fragile X molecular analysis & $67(79.8)$ & 0 \\
FISH for 15q duplication & $20(23.8)$ & 0 \\
FISH for distal 22q13 deletion & $29(34.5)$ & 0 \\
FISH for Smith-Magenis syndrome & $6(7.1)$ & 0 \\
Subtelomeric FISH analysis & $4(4.8)$ & 0 \\
Metabolic screen (lactate, & $53(63.1)$ & $1(1.9)$ \\
$\quad$ ammonia, plasma amino acids, & & 0 \\
Urine purines and pyrimidines & $13(15.5)$ & 3 \\
MECP2 sequencing & $6(7.1)$ & 1 \\
Skin fibroblast karyotype analysis & $2(2.4)$ & 0 \\
UPD methylation analysis & $1(1.2)$ & 0 \\
FRAXE molecular analysis & $1(1.2)$ & 0 \\
Glycosylated transferrin level & $1(1.2)$ & 0 \\
Serum biotinidase level & $1(1.2)$ &
\end{tabular}

ammonia level, plasma and urine amino acids, urine purines and pyrimidines, and urine homocitrulline level. Several quantitative urine orotic acid measurements have consistently shown elevations ranging from 9.7 to $16 \mathrm{mmol} / \mathrm{mol} /$ creatinine. Sequencing of ornithine transcarbamylase did not reveal any mutations. The association of elevated urine orotic acid in the presence of a normal ammonia is still unclear.

\section{DISCUSSION}

In our patient population, the frequency of identifying a genetic cause in children with autistic features who do not necessarily meet DSM-IV criteria is similar to yields identified in other studies that used more stringent criteria. Chudley et al. published the first retrospective analysis in a series of 91 children who met DSM-IIIR criteria for PDD. ${ }^{3}$ A recognizable syndrome was detected in 14 children (15.4\%), including four children with a chromosomal abnormality and five females with Rett syndrome. The remainder were two children with fragile X syndrome, two patients with metabolic abnormalities of questionable clinical significance, and one child with tuberous sclerosis complex.

Voigt et al. evaluated the utility of laboratory testing in children with autistic spectrum disorders. ${ }^{4}$ The criteria for inclusion was based on meeting DSM-IIIR or DSM-IV criteria for a diagnosis of autism or PDD not otherwise specified. Other PDDs were excluded. Among 168 patients referred, 97 patients underwent laboratory evaluation. Six patients (6\%) were found to have chromosomal abnormalities including Klinefelter syndrome, fragile X syndrome (by karyotype), and mosaic trisomy 21 among others, but the degree of mosaicism was not reported. Two additional patients were found to have fragile $\mathrm{X}$ syndrome on molecular testing. None of the patients tested had abnormal metabolic studies.

The low identification of dysmorphic features in our patient population is likely the result of an ascertainment bias. Because most children with striking facial features will be referred for that reason, it is unlikely that the primary or secondary reason for referral recorded in our database would be for autism or autistic-like features. Miles and Hillman examined the utility of a clinical morphology examination in children with autism. ${ }^{5}$ In their population of 94 patients, $54 \%$ were described as having normal morphology. Twenty percent of patients were defined as having abnormal morphology, $19 \%$ as having equivocal morphology, and $6 \%$ as having findings suggestive of a genetic syndrome. When the results of the external physical examination and the magnetic resonance imaging of the brain were combined, correlation was noted between the normal and abnormal morphology groups. However, intelligence quotient scores varied with each phenotypic group. This suggests that abnormal morphology correlates with structural changes in other organ systems such as the brain. However, abnormal structure is not necessarily an accurate representation of function. Likewise, the absence of dysmorphic features, particularly in our patient population, does not exclude the possibility of a chromosomal abnormality.

Our yield of $8.3 \%$ is consistent with the published range of $6 \%$ to $15 \%$ despite including patients who did not necessarily meet DSM criteria. This suggests that all patients with autisticlike features, even if they do not meet criteria, would benefit from a genetics evaluation. Autistic features seem to be a marker of abnormal brain development, which would suggest an underlying genetic cause, despite the severity of symptoms or degree of impairment. The current classification of the PDDs continues to be primarily useful for treatment, and less important in regard to the pathogenesis of these heterogeneous conditions.

Presumably, the absence of children with fragile X syndrome is likely because of the awareness of pediatric practitioners in our area. Frequently, patients with significant developmental delay or mental retardation are referred to our institution after such testing has already been performed. In the event of a positive result, the referral to the genetics clinic is usually for fragile $\mathrm{X}$ syndrome, and not for the presenting symptoms. Therefore, those patients were not ascertained by the database search method used in this study. Other large series performed to date have consistently shown detection rates of $1 \%$ to $2 \% .^{3,4}$

One patient had an unbalanced 10;22 translocation that was not detected on routine karyotype analysis. Because patients with minimal dysmorphic features are unlikely to have large chromosomal deletions or duplications, this patient emphasizes the need to obtain high-resolution studies in patients presenting primarily for PDD or autistic features. One child was identified with a duplication of the terminal portion of the 
Table 3

List of the diagnoses and associated features

\begin{tabular}{|c|c|c|c|c|c|c|c|}
\hline Diagnosis & $\begin{array}{c}\text { No. diagnoses } \\
(\%)\end{array}$ & $\begin{array}{l}\text { No. tested } \\
\quad(\%)\end{array}$ & Autism diagnosis & Associated features & OFC & $\begin{array}{l}\text { Male:Female } \\
\text { ratio }\end{array}$ & $\begin{array}{l}\text { No. with positive } \\
\text { family history }^{a}\end{array}$ \\
\hline \multicolumn{8}{|l|}{ Chromosomal } \\
\hline $\begin{array}{l}\text { 46,XX,dup (5) } \\
\text { (p15.33pl14) }\end{array}$ & & & Autistic disorder & $\begin{array}{l}\text { Ptosis, clinodactyly, } \\
\text { seizures }\end{array}$ & $50^{\text {th }}-98^{\text {th }}$ centile & & \\
\hline $46, \mathrm{XX} / 47, \mathrm{XX}+21$ & $3 / 84(3.6)$ & $3 / 83(3.6)$ & Autistic features & $\begin{array}{l}\text { Epicanthal folds, } \\
\text { seizures }\end{array}$ & $50^{\text {th }}-98^{\text {th }}$ centile & $1: 2$ & $2 / 3$ \\
\hline $\begin{array}{l}\text { 46,XX,der(22)t(10;22) } \\
\quad(\mathrm{q} 26.1 ; \mathrm{q} 13.3) \mathrm{mat}\end{array}$ & & & Autistic features & None & $2^{\text {nd }}-50^{\text {th }}$ centile & & \\
\hline \multicolumn{8}{|l|}{ Rett syndrome } \\
\hline 852delAAAG & & & Autistic features & Regression & $2^{\text {nd }}-50^{\text {th }}$ centile & & \\
\hline $\mathrm{R} 270 \mathrm{X}$ & $3 / 84(3.6)$ & $3 / 6$ & Autistic features & Regression & $<2^{\text {nd }}$ centile & $0: 3$ & $0 / 3$ \\
\hline R168X & & & Autistic features & None & $3-5^{\text {th }}$ centile & & \\
\hline Elevated orotic acid & $1 / 84(1.2)$ & $1 / 53(1.9)$ & Autistic disorder & None & $75^{\text {th }}$ centile & $0: 1$ & $0 / 1$ \\
\hline Total with diagnoses & $7 / 84(8.3)$ & & & & & & \\
\hline $\begin{array}{c}\text { Total without } \\
\text { diagnoses }\end{array}$ & 77/84 (91.7) & & & & & & \\
\hline
\end{tabular}

${ }^{a}$ Includes other individuals with autism, developmental delay, mental retardation, or recurrent miscarriages.

short arm of chromosome 5. This duplication has not been described in autistic individuals.

The testing algorithm used by geneticists can be dependent on the patient's presentation. However, all of our clinicians have a very similar approach to autistic individuals. Nearly all patients underwent a karyotype analysis. The number of fragile $\mathrm{X}$ tests performed is reflective of the male predominance of our population. A smaller number of FISH analyses to exclude $22 \mathrm{q} 13$ deletion and $15 \mathrm{q}$ duplication were performed because of the recent identification of these associations. ${ }^{6,7}$ Deletion 22q13 syndrome is characterized by absent speech, mild hypotonia, abnormalities of the pinnae, and hypoplastic nails. ${ }^{8}$ The clinical phenotype is difficult to detect except for absent speech. This feature prompts care providers to classify such children as autistic. Therefore, we continue to recommend FISH analysis for 22q13 to detect this subtle phenotype. Chromosome 15q aberrations have been described in association with autism in a number of case reports. Schroer et al. screened 100 patients from the South Carolina Autism Project and detected four patients with chromosome 15 aberrations, including two duplications and two deletions of the maternal allele. ${ }^{9}$ On the basis of these findings, chromosome 15 abnormalities were considered the single most common cause of autism. Screening of an additional 89 patients identified only one other patient (Roger E. Stevenson, personal communication). Nevertheless, the frequency for these abnormalities is high enough to warrant screening all autistic patients with FISH for the $15 q$ region.

Studies evaluating the utility of subtelomeric FISH analysis for children with autism have been lacking. However, one series evaluated 49 children with autistic disorder using subtelomeric FISH. ${ }^{10}$ No abnormalities were detected in that study.
This is consistent with the lack of subtelomeric rearrangements detected in our cohort.

The absence of patients with significant metabolic findings in these series suggests that screening for metabolic disorders is not necessarily warranted for all patients with PDDs. By using a more selective approach, one may reduce the number of unnecessary and expensive tests in patients with no suggestive findings. Shevell et al. performed a prospective analysis of 50 patients referred to a neurology clinic for PDD/autism or autistic features. ${ }^{11}$ They did not identify any metabolic disorders in their population and suggested that the use of widespread screening of autistic children is less than 5\%. However, it should be noted that, recently, patients with purine and pyrimidine metabolic defects have presented primarily with autistic features. ${ }^{12}$ In our series, only 13 patients underwent such testing because this is a less-known entity, and no abnormalities were identified. There are not enough data at this time to make general recommendations for purine/pyrimidine analysis. Additional evidence has also revealed the presence of mitochondrial disorders in autistic patients such as mitochondrial DNA depletion and complex III defects in association with inverted $15 \mathrm{q}$ duplications..$^{13,14}$ The applicability of such information to routine clinical practice remains unclear at the present time.

Surprisingly, a number of patients with Rett syndrome continue to be identified in this population of patients. In our series, patients who presented early were usually difficult to identify. As these patients progress through the third and fourth years of life, more characteristic findings become apparent. In this case, it seems that MECP2 sequencing may be warranted in developmentally delayed females who present before the age of 4 years. Carney et al. used very strict criteria to identify 69 females with autistic disorder and screened them for 
MECP2 mutations. ${ }^{15}$ Two of 69 patients (3\%) were found to have disease-causing mutations. The clinical phenotypes were not characteristic of Rett syndrome. Because the DSM-IV criteria lists the diagnosis of Rett syndrome as exclusionary for $\mathrm{PDD}$, it may be helpful to change this criteria to specify the presence of a MECP2 mutation. Including a greater amount of molecular data would assist the DSM transition to more etiologically based criteria. Eventually, therapeutic regimens could be better designed, and clinical trials of potential medications may benefit from such restructuring.

In summary, our current recommendations regarding laboratory evaluation of patients with the PDDs are based on the present study and a review of the literature. We suggest performing a high-resolution karyotype in all patients, especially because the 10;22 unbalanced translocation in our patient was not identified with routine karyotype analysis. Fragile $\mathrm{X}$ testing should continue to be performed routinely according to previous studies. FISH for $22 \mathrm{q} 13$ deletion and $15 \mathrm{q}$ duplication is essential because these disorders are not associated with an obvious clinical phenotype. MECP2 sequencing should be considered in younger females who present with autistic features and developmental delay. Metabolic studies should be performed in the presence of suggestive findings, and more specialized testing should be based on the clinician's judgment.

\section{References}

1. Ritvo E, Jorde LB, Mason-Brothers A, Freeman BJ et al. The UCLA-University of Utah epidemiological survey of autism: recurrence risk estimates and genetic counselling. Am J Psychol 1989;146:194-199.
2. Bailey A, Le Couteur A, Gottesman I, Bolton P et al. Autism as a strongly genetic disorder: evidence from a British twin study. Psychol Med 1995;25:63-77.

3. Chudley A, Gutierrez E, Jocelyn LJ, Chodirker BN. Outcomes of genetic evaluation in children with pervasive developmental disorder. Dev Behav Pediatr 1998;19:321-325.

4. Voigt RG, Dickerson CL, Reynolds AM, Childers DO et al. Laboratory evaluation of children with autistic spectrum disorders: a guide for primary care pediatricians. Clin Pediatr 2000;39:669-671.

5. Miles JH, Hillman RE. Value of a clinical morphology examination in autism. Am J Med Genet 2000;91:245-253.

6. Prasad C, Prasad AN, Chodirker BN, Lee C et al. Genetic evaluation of pervasive developmental disorders: the terminal 22q13 deletion syndrome may represent a recognizable phenotype. Clin Genet 2000;57:103-109.

7. Bolton PF, Dennis NR, Browne CE, Thomas NS et al. The phenotypic manifestations of interstitial duplications of proximal $15 \mathrm{q}$ with special reference to the autistic spectrum disorders. Am J Med Genet 2001;105:675-685.

8. Manning MA, Cassidy SB, Clericuzio C, Cherry AM et al. Terminal 22q deletion syndrome: a newly recognized cause of speech and language disability in the autism spectrum. Pediatrics 2004;114:451-457.

9. Schroer RJ, Phelan MC, Michaelis RC, Crawford EC et al. Autism and maternally derived aberrations of chromosome 15q. Am J Med Genet 1998;76:327-336.

10. Keller K, Williams C, Wharton P, Paulk M et al. Routine cytogenetic and FISH studies for $17 \mathrm{p} 11 / 15 \mathrm{q} 11$ duplications and subtelomeric rearrangement studies in children with autistic spectrum disorders. Am J Med Genet 2003;117A:105111.

11. Shevell MI, Majnemer A, Rosenbaum P, Abrahamowicz M. Etiologic yield of autistic spectrum disorders: a prospective study. J Child Neurol 2001;16:509-512.

12. Simmonds HA, Duley JA, Fairbanks LD, McBride MB. When to investigate for purine and pyrimidine disorders. Introduction and review of clinical and laboratory indications. J Inherit Metab Dis 1997;20:214-226.

13. Pons R, Andreu AL, Checcarelli N, Vila MR et al. Mitochondrial DNA abnormalities and autistic spectrum disorders. J Pediatr 2004;144:81-85.

14. Filipek PA, Juranek J, Smith M, Mays LZ et al. Mitochondrial dysfunction in autistic patients with 15q inverted duplication. Ann Neurol 2003;53:801-804.

15. Carney RM, Wolpert CM, Ravan SA, Shahbazian M et al. Identification of MECP2 mutations in a series of females with autistic disorder. Pediatr Neurol 2003;28: 205-211. 